\title{
Patient and health system factors associated with pretreatment loss to follow up among patients diagnosed with tuberculosis using Xpert $^{\circledR}$ MTB/RIF testing in Uganda
}

Stella Zawedde-Muyanja ${ }^{* *}$ (D) Achilles Katamba², Adithya Cattamanchi ${ }^{3}$, Barbara Castelnuovo ${ }^{1}$ and Yukari C. Manabe ${ }^{4}$

\begin{abstract}
Background: In 2018, Uganda started only $65 \%$ of persons with incident tuberculosis on treatment. Pretreatment loss to follow up is an important contributor to suboptimal treatment coverage. We aimed to describe the patient and health facility-level characteristics associated with pretreatment loss to follow up among patients diagnosed with pulmonary tuberculosis at public health facilities in Uganda.

Methods: At ten public health facilities, laboratory register data was used to identify patients aged $\geq 15$ years who had a positive Xpert ${ }^{\oplus}$ MTB/RIF test. Initiation on TB treatment was ascertained using the clinical register. Factors associated with not being initiated on TB treatment within two weeks of diagnosis were examined using a multilevel logistic regression model accounting for clustering by health facility.

Results: From January to June 2018, 510 patients (61.2\% male and 31.5\% HIV co-infected) were diagnosed with tuberculosis. One hundred (19.6\%) were not initiated on TB treatment within 2 weeks of diagnosis. Not having a phone number recorded in the clinic registers (aOR 7.93, 95\% Cl 3.93-13.05); being HIV-infected (aOR 1.83; 95\% Cl: 1.09-3.26) and receiving care from a high volume health facility performing more than 12 Xpert tests per day (aOR $4.37,95 \% \mathrm{Cl} 1.69-11.29)$ and were significantly associated with pretreatment loss to follow up.

Conclusion: In public health facilities in Uganda, we found a high rate of pretreatment loss to follow up especially among TBHIV co-infected patients diagnosed at high volume health facilities. Interventions to improve the efficiency of Xpert ${ }^{\oplus}$ MTB/RIF testing, including monitoring of the TB care cascade should be developed and implemented.
\end{abstract}

Keywords: Pretreatment loss to follow-up, Xpert testing, Tuberculosis, Uganda

\footnotetext{
* Correspondence: szawedde@idi.co.ug

${ }^{1}$ The Infectious Diseases Institute, College of Health Sciences, Makerere University, P.O. Box 22418, Kampala, Uganda

Full list of author information is available at the end of the article
}

C C The Author(s). 2020 Open Access This article is licensed under a Creative Commons Attribution 4.0 International License, which permits use, sharing, adaptation, distribution and reproduction in any medium or format, as long as you give appropriate credit to the original author(s) and the source, provide a link to the Creative Commons licence, and indicate if changes were made. The images or other third party material in this article are included in the article's Creative Commons licence, unless indicated otherwise in a credit line to the material. If material is not included in the article's Creative Commons licence and your intended use is not permitted by statutory regulation or exceeds the permitted use, you will need to obtain permission directly from the copyright holder. To view a copy of this licence, visit http://creativecommons.org/licenses/by/4.0/. The Creative Commons Public Domain Dedication waiver (http://creativecommons.org/publicdomain/zero/1.0/) applies to the data made available in this article, unless otherwise stated in a credit line to the data. 


\section{Background}

Uganda is one of the 30 high tuberculosis(TB) and HIV burden countries [1]. In 2015, the estimated TB incidence was $253 / 100,000$ population, a rate higher than previously projected [2]. The end TB strategy mandates a $90 \%$ reduction in TB incidence (compared to 2015) by 2035 [3]. In order to achieve this target, high burden countries including Uganda must break the transmission cycle by diagnosing and placing on appropriate therapy, at least $90 \%$ of all persons with TB annually [3]. However, TB treatment coverage (the ratio of notified to estimated persons with TB) in Uganda has been persistently low and in 2018, only $65 \%$ of all estimated persons with TB were started on treatment by the National TB and Leprosy Program (NTLP) [1].

Persistently low TB treatment coverage is a result of a leaky "cascade of care". The "cascade of care" is a series of sequential steps that patients must successfully complete in order to achieve a desired outcome (cure or control) for a disease of interest [4]. The TB cascade of care, derived from the World Health Organization (WHO) Onion model [5] outlines the implementation steps for patients to achieve TB cure: they must recognize $\mathrm{TB}$ signs and symptoms; present to health facilities; be recognized by the healthcare system; receive a microbiological test for TB; be started on TB treatment and be retained in care for the entire duration of treatment. Previous studies have shown that a significant proportion of $\mathrm{TB}$ patients do not recognize the signs and symptoms of $\mathrm{TB}$ and therefore do not present to the healthcare system $[2,6]$. Of those who present, only $20 \%$ of receive a microbiological test for TB $[2,7,8]$. Of those tested and diagnosed with TB, 20-25\% never start treatment as a result of pretreatment loss to followup(LFU) $[4,7,9]$.

Pretreatment LFU is defined as the loss of patients between diagnosis with $\mathrm{TB}$ and treatment initiation and is a critical point of attrition in the "cascade of care". Patients who are lost to follow-up before starting TB therapy continue to transmit within communities and have significantly worse disease outcomes including death [7]. In other settings, pretreatment LFU has been associated with older age ( $>45$ years), male sex, and receiving care from high volume tertiary hospitals [10-12]. We sought to describe patient and health facility level characteristics associated with pretreatment LFU up among patients with pulmonary bacteriologically confirmed (PBC) TB using Xpert $^{\circ} \mathrm{MTB} / \mathrm{RIF}$ testing at public health facilities in Uganda.

\section{Methods}

\section{Study setting}

Healthcare delivery in Uganda is tiered with primary, secondary and tertiary levels of care. Within the healthcare system, TB care services are provided at all secondary and tertiary levels of care, as well as selected primary care facilities. Over the past five years, sputum microscopy, previously the main diagnostic test for TB, has been increasingly replaced by Xpert ${ }^{\circ} \mathrm{MTB} /$ RIF testing. To date, about 235 health facilities (15\% of all health facilities which offer TB care services) are equipped with Xpert $^{\circ} \mathrm{MTB} / \mathrm{RIF}$ machines. At these health facilities, Xpert ${ }^{\circ} \mathrm{MTB} / \mathrm{RIF}$ testing is the initial diagnostic test for all patients with signs and symptoms of TB [13]. Health facilities which do not have Xpert ${ }^{\circ} \mathrm{MTB} / \mathrm{RIF}$ machines use sputum microscopy as the mainstay of diagnosis, but access Xpert ${ }^{\circ}$ MTB/RIF testing for selected patient populations (e.g., patients infected with HIV and those previously treated for $\mathrm{TB}$ ) through a specimen referral system. Health facilities with Xpert ${ }^{\circ}$ MTB/RIF testing act as "diagnostic hubs" for lower health facilities within a $20-30 \mathrm{~km}$ radius. Sputum samples are transported by motorcycle to the diagnostic hubs and results are returned to the referring health facilities by the same courier. All patients diagnosed with TB are recorded in standardized paper-based national register.

Unless there is an indication for hospital admission, TB treatment is offered free-of-charge in the outpatient setting. The Uganda National TB and Leprosy program (NTLP) recommends that all patients diagnosed with drug-susceptible TB are started on treatment as soon as possible, preferably within $24 \mathrm{~h}$ [13]. For patients who prefer to complete TB treatment at a health facility other than the one where TB diagnosis is made, the NTLP still recommends that TB treatment is started at the diagnosing facility and the patient is subsequently referred to the health facility of their choice.

The NTLP uses separate national, standardized, paperbased registers for recording and reporting: all patients with signs and symptoms of TB (TB presumptive registers); all patients with a bacteriological confirmation of TB (TB laboratory registers); and all patients started on TB treatment ( $\mathrm{TB}$ treatment registers). These registers are present at all health facilities where $\mathrm{TB}$ services are offered. Data for all patients started on TB treatment within each district is collated into one district $\mathrm{TB}$ register periodically to allow for recording of treatment outcome data for patients who may have started or completed TB treatment at a different health facility than the one where they were diagnosed.

To get a representative picture of the healthcare system, we purposively selected for this study, health facilities from different levels of the healthcare system (three primary care facilities, four district hospitals and three tertiary referral hospitals) across ten districts in Uganda. All facilities in this study have Xpert ${ }^{\circ}$ MTB/RIF testing available onsite and use this test as the initial diagnostic test for patients presenting with signs and symptoms of 
TB [13]. All facilities in this study also act as diagnostic hubs and receive additional samples for testing from primary care facilities within their catchment area.

\section{Data collection}

We carried out a retrospective review of data collected at the selected health facilities between January 1st and June 30th, 2018. We used data from laboratory registers to identify patients aged $\geq 15$ years who had a positive Xpert ${ }^{\circ} \mathrm{MTB} / \mathrm{RIF}$ test and were rifampicin sensitive. We excluded all patients who had an Xpert ${ }^{\circ} \mathrm{MTB} / \mathrm{RIF}$ test done as part of treatment monitoring. We then compared diagnostic data with treatment initiation records in the health facility TB treatment registers and in the district TB registers (for patients who could have started on TB treatment at a different health facility within the same district). Patients were considered to have experienced pretreatment LFU if their names were in the laboratory register but no evidence of their names in the health facility clinic or district $\mathrm{TB}$ registers within 2 weeks of diagnosis.

Data on patient characteristics including age, sex, HIV status, ART status, and residence was collected from the laboratory registers. Patient's age was categorized in 10year age groups starting at 15 years in according to the practices on case notifications at the district and national level. Distance to the health facility was calculated as the linear distance, based on global positioning system coordinates (QGIS Desktop, Versions 2.12.0), from the patient's recorded residence to the health facility.

Health facility records were used to obtain data on health facility characteristics including the number of
Xpert $^{\circ} \mathrm{MTB} / \mathrm{RIF}$ tests done, cartridge and medicine stock outs. Data on cartridge malfunction was collected by interviewing laboratory healthcare workers at each health facility.

\section{Data analysis}

Baseline characteristics of the study population were described using frequencies and percentage. The proportion of patients who experienced pretreatment LFU was also described. A multilevel logistic regression model accounting for clustering by health facility was used to examine factors associated with pretreatment loss to follow up. A sensitivity analysis was performed using multiple imputation to examine the effect of missing data on our measures of association. For variables with missing data (distance from health facility, HIV status and ART status), we assumed data were missing at random and performed multivariate normal imputation [14] using age, sex and level of health facility as predictor variables. All data analyses were carried out using STATA ${ }^{\circ}$ version 13.

\section{Results}

From January to June 2018, 6721 persons with presump-

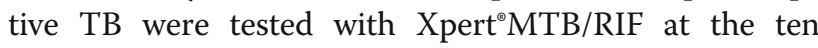
health facilities. Of these, 510 (7.6\%) tested positive for MTB and 410 (80.4\%) were started on TB treatment. (Fig. 1).

Table 1 shows the characteristics of study participants. Patients enrolled in the study were predominantly male (61.2\%). The majority $(N=244,47.9 \%)$ were diagnosed at tertiary referral hospitals. Only a third of all patients

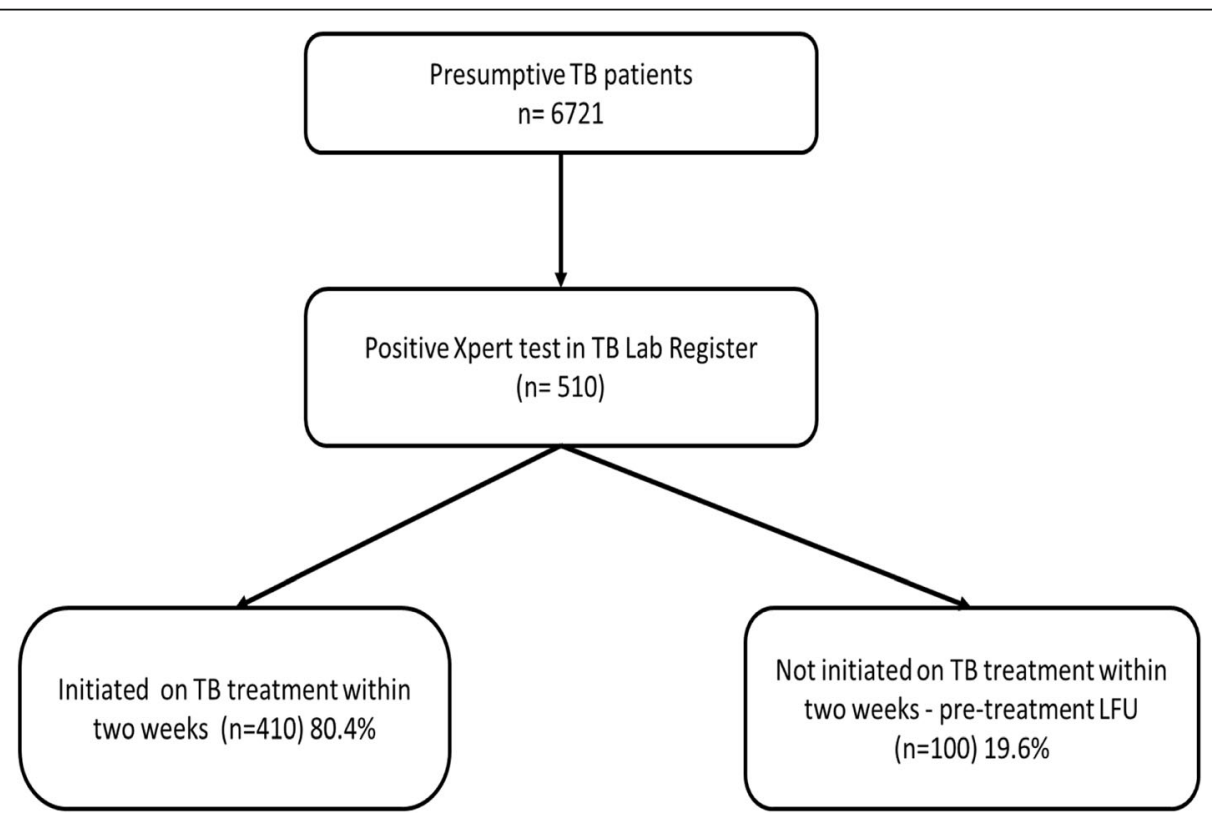

Fig. 1 Patient Flow Chart 
Table 1 Characteristics of Study Participants

\begin{tabular}{ll}
\hline Individual Level Characteristics $(\boldsymbol{N}=\mathbf{5 1 0})$ & $\mathbf{N}(\%)$ \\
\hline Characteristic & \\
\hline Sex & $312(61.2)$ \\
$\quad$ Male & $198(38.8)$ \\
$\quad$ Female & \\
Age & $115(22.7)$ \\
$15-24$ & $162(31.7)$ \\
$25-34$ & $111(21.7)$ \\
$35-44$ & $66(12.9)$ \\
$45-54$ & $56(10.9)$ \\
$>55$ &
\end{tabular}

Phone No.

Yes

No

Distance from health facility $(n=469)$

$<=5 \mathrm{~km}$

6-20 km

$21-35 \mathrm{~km}$

$>35 \mathrm{~km}$

HIV status $(n=479)$

HIV positive

HIV negative

ART Status $(n=138)$

On ART before TB diagnosis

Started ART after TB diagnosis

Facility Level Characteristics

Characteristic

Health Facility Level

Primary care Facility

District Hospital

Tertiary Hospital

Number of Xpert tests done

$<=8$ tests/day

9-12 tests/day

$>12$ tests/day

Xpert Turnaround time

$$
<24 \mathrm{~h}
$$

$24-48 h$

$$
>48 \mathrm{~h}
$$

Xpert Module Malfunction (past 3 months)

No

Yes

Cartridge Stock Outs (past 3 months)

$89(17.4)$

$79(15.5)$
Table 1 Characteristics of Study Participants (Continued) Individual Level Characteristics $(N=510)$

\begin{tabular}{ll}
\hline Characteristic & N (\%) \\
\hline Medicine Stock out (past 3 months) & \\
Yes & $67(13.1)$ \\
No & $443(86.9)$ \\
\hline
\end{tabular}

were started on TB treatment on the same day. HIV status was available for 479 (94.0\%) study participants and $161(31.5 \%)$ of these were HIV co-infected. ART status was available for 138 (85.7\%) HIV co-infected patients. Among these, 101 (73.2\%) were on ART prior to starting TB treatment while 37 (26.8\%) were newly diagnosed with HIV and initiated ART after starting TB treatment (Table 2).

Overall, 100 (19.6\%) patients were not initiated on TB treatment within 2 weeks of diagnosis (Fig. 1). On bivariate analysis, patient-level factors associated with pretreatment LFU included not having a phone number listed in the TB clinic register (OR 8.99, 95\%CI 5.1715.64) and being HIV-infected (OR 1.86; 95\% CI: 1.10 3.12) (Table 2). Facility-level factors (Table 3) associated with pretreatment LFU included being diagnosed at a health facility performing $>12$ Xpert tests per day (OR $2.30,95 \%$ CI 1.77-2.99); being diagnosed at a health facility with Xpert cartridge stock outs in the past 3 months (OR 1.63; 95\% CI: 1.04-2.54); and being diagnosed at a health facility which experienced module malfunction in the past 3 months (OR 2.11; 95\% CI: 2.53-2.89).

In the adjusted analysis (Tables 2 and 3), only three factors - not having a phone number listed in the TB clinic register (aOR 7.93, 95\% CI 3.93-13.05); being HIVinfected (aOR 1.83; 95\% CI: 1.09-3.26) and being diagnosed at a health facility performing more than 12 Xpert tests per day (aOR 4.37, 95\%CI 1.69-11.29) remained significantly associated with pretreatment LFU. In sensitivity analyses using multiple imputation, all significant associations were maintained (Supplementary Tables 1 \& 2).

\section{Discussion}

In this retrospective study we examined patient and health facility factors associated with pretreatment LFU at public health facilities in Uganda; we found that about one in five patients diagnosed with TB experienced pretreatment LFU. Pretreatment LFU is a persistent problem in public health systems high TB burden settings [15-17]. In India, one of the countries with the highest TB burden in the world, pretreatment LFU is estimated to be responsible for at least $8 \%(200,000)$ of all missing persons with TB annually [4]. In our study, the observed proportion of patients experiencing pretreatment LFU 
Table 2 Patient level factors associated with pretreatment loss to follow up in a multilevel logistic regression model

\begin{tabular}{|c|c|c|c|c|}
\hline Characteristic & $\begin{array}{l}\text { Initiated on } \mathrm{Rx} \\
N=410\end{array}$ & $\begin{array}{l}\text { Not Initiated on Rx } \\
N=100\end{array}$ & $\begin{array}{l}\text { Crude Odds Ratio } \\
(95 \% \mathrm{Cl})\end{array}$ & $\begin{array}{l}\text { Adjusted Odds Ratio } \\
(95 \% \mathrm{Cl})\end{array}$ \\
\hline \multicolumn{5}{|l|}{ Sex } \\
\hline Male & $256(82.1)$ & $57(17.9)$ & reference & - \\
\hline Female & $154(77.8)$ & $43(22.2)$ & $1.30(0.84-2.04)$ & - \\
\hline \multicolumn{5}{|l|}{ Age } \\
\hline $15-24$ & $92(80.0)$ & $23(20.0)$ & reference & - \\
\hline $25-34$ & $130(80.3)$ & $32(19.7)$ & $0.98(0.54-1.79)$ & - \\
\hline $35-44$ & $91(81.9)$ & $20(18.1)$ & $0.88(0.45-1.70)$ & - \\
\hline $45-54$ & $51(77.2)$ & $15(22.8)$ & $1.17(0.56-2.46)$ & - \\
\hline$>55$ & $46(82.1)$ & $10(17.9)$ & $0.88(0.39-2.00)$ & - \\
\hline \multicolumn{5}{|l|}{ Phone No. } \\
\hline Yes & $298(92.3)$ & $25(8.7)$ & reference & reference \\
\hline No & $112(59.9)$ & $75(40.1)$ & $8.99(5.17-15.64)$ & $7.93(3.93-13.05)$ \\
\hline \multicolumn{5}{|l|}{ aDistance from health facility $(n=469)$} \\
\hline$>35 \mathrm{~km}$ & $64(87.7)$ & $9(12.3)$ & reference & - \\
\hline $21-35 \mathrm{~km}$ & $124(87.3)$ & $18(12.7)$ & $1.04(0.44-2.49)$ & - \\
\hline $6-20 \mathrm{~km}$ & $106(86.9)$ & $16(13.1)$ & $1.12(0.47-2.69)$ & - \\
\hline$<=5 \mathrm{~km}$ & $103(81.9)$ & $29(18.1)$ & $2.08(0.93-4.67)$ & - \\
\hline \multicolumn{5}{|l|}{ bHIV status $(n=479)$} \\
\hline HIV negative & $281(88.4)$ & 37 (11.6) & reference & reference \\
\hline HIV positive & $129(80.1)$ & $32(19.9)$ & $1.86(1.10-3.12)$ & $1.88(1.09-3.26)$ \\
\hline \multicolumn{5}{|l|}{${ }^{c}$ ART Status $(n=138)$} \\
\hline On ART before TB diagnosis & $91(90.1)$ & $10(9.9)$ & reference & - \\
\hline Not on ART before TB diagnosis & $34(91.9)$ & $3(8.1)$ & $0.61(0.14-2.61)$ & - \\
\hline
\end{tabular}

would translate into $11 \%(10,000)$ of all missing persons with TB countrywide in that period.

Earlier studies examining pretreatment LFU among patients diagnosed with sputum microscopy showed that increased time and monetary costs associated with returning to health facilities to deliver a second sputum sample and/or collect sputum results were partly responsible for observed high rates of pretreatment LFU $[8,18,19]$. Xpert ${ }^{\circ} \mathrm{MTB} / \mathrm{RIF}$ testing, a near POC test that requires only one sputum sample and has relatively quick turnaround times held the promise of reducing pretreatment LFU. Results from one clinical trial conducted in South Africa showed a reduction in pretreatment LFU driven by the increased proportion of patients who received a same-day diagnosis [20]. However, this finding has not been replicated in routine care settings both in South Africa and Uganda [16, 21, 22]. Patients accessing Xpert ${ }^{\circ} \mathrm{MTB} / \mathrm{RIF}$ testing in our setting still experience relatively long turnaround times [21]. In our study, only one-third of patients received a same-day diagnosis.
High patient volumes (measured in our study by the number of $\mathrm{Xpert}^{\ominus} \mathrm{MTB} / \mathrm{RIF}$ tests run each day) likely prolong the turnaround time for Xpert $^{\circ}$ MTB/RIF testing, and result in more patients experiencing pretreatment LFU. This association between high patient volumes and pretreatment LFU has been shown in Asia and other parts of sub-Saharan Africa [10, 11, 23, 24] and has been attributed to prolonged clinic waiting times, and increased laboratory turnaround times for sputum microscopy. In the Ugandan setting, high patient loads also make it harder to monitor treatment initiation among patients diagnosed with TB. The current system to monitor treatment initiation requires healthcare workers to manually reconcile laboratory registers with treatment registers, a task that may be difficult to perform regularly at health facilities with high patient volumes. At these health facilities, electronic systems that carry out real time monitoring of patient retention along the cascade of care could lead to reductions in pretreatment LFU. Although these kinds of electronic data 
Table 3 Health facility factors associated with pretreatment loss to follow up in a multilevel logistic regression model.

\begin{tabular}{|c|c|c|c|c|}
\hline Characteristic & $\begin{array}{l}\text { Initiated on } \mathrm{Rx} \\
N=410\end{array}$ & $\begin{array}{l}\text { Not Initiated on Rx } \\
N=100\end{array}$ & $\begin{array}{l}\text { Crude Odds Ratio } \\
(95 \% \mathrm{Cl})\end{array}$ & $\begin{array}{l}\text { Adjusted Odds Ratio } \\
(95 \% \mathrm{Cl})\end{array}$ \\
\hline \multicolumn{5}{|c|}{ Number of Xpert tests done } \\
\hline$<=8$ tests/day & $280(81.9)$ & $62(18.1)$ & reference & reference \\
\hline 9-12 tests/day & $77(86.5)$ & $12(13.5)$ & $0.84(0.69-1.00)$ & $0.53(0.24-1.17)$ \\
\hline$>12$ tests/day & $53(67.1)$ & $26(32.9)$ & $2.30(1.77-2.99)$ & $4.37(1.69-11.29)$ \\
\hline \multicolumn{5}{|c|}{ Xpert module malfunction (past 3 months) } \\
\hline No & $295(82.9)$ & $61(17.1)$ & reference & reference \\
\hline Yes & $115(74.7)$ & $39(25.3)$ & $1.63(1.04-2.54)$ & $1.57(0.86-2.85)$ \\
\hline \multicolumn{5}{|c|}{ Cartridge stock outs (past 3 months) } \\
\hline No & $115(72.8)$ & $43(27.2)$ & reference & reference \\
\hline Yes & $295(83.8)$ & $57(16.2)$ & $2.11(1.53-2.89)$ & $1.59(0.88-2.86)$ \\
\hline \multicolumn{5}{|c|}{ Medicine stock out (past 3 months) } \\
\hline No & $357(80.6)$ & $86(19.4)$ & reference & - \\
\hline Yes & $53(79.1)$ & $14(20.9)$ & $1.11(0.56-2.18)$ & - \\
\hline
\end{tabular}

innovations are commonplace in HIV care, they remain largely unutilized for TB care [25].

$\mathrm{HIV}$-infected patients had higher rates of pretreatment LFU in our study consistent with data from other high TBHIV burden settings $[17,26]$. Late presentation to care could partially account for these LFU patients. In Malawi, advanced HIV disease was shown to result in suboptimal linkage to TB treatment as patients were often too sick to return to the health facility for their results or died before treatment initiation [18]. In Zimbabwe, close to $50 \%$ of pretreatment LFU was due to deaths before treatment initiation particularly among HIV-infected patients [17]. In our study, late presentation to care was examined by analyzing the ART status of patients who were started on TB treatment. Among those patients whose ART status was available, about a quarter (27\%) initiated ART after starting TB treatment. This is consistent with routine surveillance data from the AIDS Control Program that shows that despite the roll out of "test and treat" for HIV, about 30\% of all newly diagnosed HIV patients still present with Stage III and IV disease [27]. The introduction of additional point-of-care tests with shorter turnaround times e.g. lateral flow urine lipoarabinomannan (LF-LAM) [28] into the diagnostic algorithm for patients with Stage III and IV disease may improve linkage to treatment among this group of patients.

In our study, patients who did not have a phone number recorded was strongly associated with pretreatment LFU. Although patients may deliberately decline to divulge their phone numbers due to self-stigma related to TB [29], the proportion of patients with a recorded phone number in our study (63\%) was comparable to the national phone coverage for rural areas (65.7\%) [30] and is therefore likely to represent actual phone ownership. Patients without phone numbers may belong to a lower socio-economic class and may lack the financial means to return to health facilities to receive their results and start on TB treatment [31]. The recently concluded patients' costs survey in Uganda showed half of all TB patients incurred catastrophic TB care costs which were mainly driven by nonmedical expenditure such as travel [32]. Interventions to reduce these costs for the most vulnerable patients e.g. prioritizing them for same-day diagnosis or provision of socioeconomic support may reduce pretreatment LFU. Similarly, community tracing interventions, where community healthcare workers conduct home visits to trace patients with no phones would also help reduce pretreatment LFU.

Consistent with studies from Ghana [10] and other settings in Uganda [33], there was no association between distance from the health facility and pretreatment LFU. This may be due to the decentralized nature of health service delivery in Uganda where patients access care at health facilities closest to their homes. In our study, nearly half of all patients resided within $20 \mathrm{kms}$ of the health facility.

\section{Study strengths and limitations}

Our study used data collected from different levels of the healthcare system. It is therefore likely that these findings are representative of and generalizable to the public healthcare system in Uganda. However, because data for this study was collected under routine programmatic conditions, missing data may have introduced bias into our study resulting in an overestimation of pretreatment LFU. This was minimized by triangulating many 
data sources within the healthcare facilities and at the district level.

\section{Conclusion}

In public health facilities in Uganda, we found a high rate of pretreatment LFU. Interventions to improve the efficiency of Xpert $^{\oplus}$ MTB/RIF testing should be developed and implemented. These efforts should be targeted at large volume tertiary hospitals and at patient groups at the highest risk of pretreatment loss to follow-up.

\section{Supplementary Information}

The online version contains supplementary material available at https://doi. org/10.1186/s12889-020-09955-0.

\section{Additional file 1: Supplementary Table 1: Patient level factors}

associated with pretreatment loss to follow-up in a multilevel logistic regression model after multiple imputation.

Additional file 2: Supplementary Table 2: Health facility level factors associated with pretreatment loss to follow-up in a multilevel logistic regression model after multiple imputation.

\section{Abbreviations}

aOR: Adjusted odds ratio; Cl: Confidence interval; HIV: Human immunodeficiency syndrome; KMS: Kilometers; LF-LAM: Lateral flow urine lipoarabinomannan; LFU: Loss to follow-up; NTLP: National TB and Leprosy program; OR: Odds ratio; TB: Tuberculosis; WHO: World Health Organization

\section{Acknowledgements}

We particularly thank the National TB and Leprosy Program for providing the data analyzed for this study.

\section{Authors' contributions}

SZ, AK and YCM conceived the study; SZM collected the data; SZM, YCM, AC and $\mathrm{BC}$ analyzed and interpreted the data. All authors contributed to the drafting and final review of the manuscript. The author (s) read and approved the final manuscript.

\section{Funding}

The authors received funding from the following sources during the drafting of this manuscript: SZM and YCM received support from the Fogarty International Center, National Institutes for Health: Grant \#D43TW009771 "HIV Co-infections in Uganda: TB, Cryptococcus and Viral Hepatitis". SZM received funding through the Sub-Saharan African Network for TB/HIV Research Excellence (SANTHE), a DELTAS Africa Initiative [grant \# DEL-15-006]. The DELTAS Africa Initiative is an independent funding scheme of the African Academy of Sciences (AAS)'s Alliance for Accelerating Excellence in Science in Africa (AESA) Agency) which is funded by the Wellcome Trust [grant \# 107752/Z/ 15/Z] and the UK government. The funding body had no role in the design of the study; collection, analysis and interpretation of the data or in the writing of the manuscript.

\section{Availability of data and materials}

The datasets used and/or analyzed during the current study are available from the corresponding author on reasonable request.

\section{Ethics approval and consent to participate}

This study used routinely collected data available in the NTLP's standardized registers used at public health facilities in Uganda. A waiver from obtaining informed consent was granted by the School of Medicine Research and Ethics Committee of the College of Health Sciences, Makerere University (2016-132) and by the Uganda National Council of Science and Technology, Kampala, Uganda (SS 4638).

\section{Consent for publication}

Not applicable.

\section{Competing interests}

The authors have no conflict of interest to declare.

\section{Author details}

${ }^{1}$ The Infectious Diseases Institute, College of Health Sciences, Makerere University, P.O. Box 22418, Kampala, Uganda. ${ }^{2}$ Department of Medicine, School of Medicine, Makerere University College of Health Sciences, Kampala, Uganda. ${ }^{3}$ Division of Pulmonary and Critical Care Medicine and Center for Tuberculosis, University of California San Francisco, San Francisco, USA. ${ }^{4}$ Division of Infectious Diseases, Department of Medicine, Johns Hopkins University School of Medicine, Baltimore, MD, USA.

Received: 19 November 2019 Accepted: 22 November 2020 Published online: 03 December 2020

\section{References}

1. World Health Organization. Global Tuberculosis Report 2019 [Internet]. 2019 278 p. Available from: https://www.who.int/tb/publications/global_report/ en/.

2. Uganda Ministry of Health. The Republic of Uganda The Uganda National Tuberculosis Prevalence Survey, 2014-2015 Survey Report [Internet] 2015. Available from: http://health.go.ug/content/uganda-national-tuberculosisprevalence-survey-2014-2015-survey-report),

3. World Health Organization. WHO End TB Strategy [Internet]. WHO. 2015 [cited 2019 Jan 21]. p. 16. Available from: https://www.who.int/tb/post2015_ strategy/en/.

4. Subbaraman R, Nathavitharana RR, Satyanarayana S, Pai M, Thomas BE, Chadha VK, et al. The tuberculosis cascade of care in India's public sector: a systematic review and meta-analysis. PLoS Med. 2016;13(10):e1002149.

5. Piot M. A simulation model for case finding and treatment in tuberculosis Programme. Bull World Health Organ. 1967;67(53):1-23.

6. Sekandi JN, Zalwango S, Martinez L, Handel A, Kakaire R, Nkwata AK, et al. Four degrees of separation: social contacts and health providers influence the steps to final diagnosis of active tuberculosis patients in urban Uganda. BMC Infect Dis. 2015;15:361.

7. Manabe YC, Zawedde-Muyanja S, Burnett SM, Mugabe F, Naikoba S, Coutinho A, et al. Rapid improvement in passive tuberculosis case detection and tuberculosis treatment outcomes after implementation of a bundled laboratory diagnostic and on-site training intervention targeting mid-level providers. Open Forum Infect Dis. 2015;2(1):ofv030. https://doi.org/10.1093/ ofid/ofv030.

8. Davis JL, Katamba A, Vasquez J, Crawford E, Sserwanga A, Kakeeto S, et al. Evaluating tuberculosis case detection via real-time monitoring of tuberculosis diagnostic services. Am J Respir Crit Care Med. 2011;184(3): 362-7.

9. Marquez C, Davis JL, Katamba A, Haguma P, Ochom E, Ayakaka I, et al. Assessing the quality of tuberculosis evaluation for children with prolonged cough presenting to routine community health care settings in rural Uganda. PLoS One. 2014;9(8):e105935.

10. Afutu FK, Zachariah R, Hinderaker SG, Ntoah-Boadi H, Obeng EA, Bonsu FA, et al. High initial default in patients with smear-positive pulmonary tuberculosis at a regional hospital in Accra, Ghana. Trans R Soc Trop Med Hyg. 2012;106(8):511-3.

11. Thomas BE, Subbaraman R, Sellappan S, Suresh C, Lavanya J, Lincy S, et al. Pretreatment loss to follow-up of tuberculosis patients in Chennai, India: A cohort study with implications for health systems strengthening. BMC Infect Dis. 2018;18(1):1-11.

12. Communication S. Initial default among cases diagnosed in the community survey and at the health facilities. Indian J Tuberc. 2005;52:153-6.

13. Uganda Ministry of Health. National Tuberculosis and Leprosy Control Programme Manual for Management and Control of TB and Leprosy. 2017; (March). Available from: www.health.go.ug/sites/default/files/NTLP Manual 3rd edition_17th Aug_final.pdf.

14. Lee KJ, Carlin JB. Multiple imputation for missing data: fully conditional specification versus multivariate normal imputation. Am J Epidemiol. 2010; 171(5):624-32.

15. MacPherson P, Houben RMGJ, Glynn JR, Corbett EL, Kranzer K. Pérdida de seguimiento antes del tratamiento de pacientes con tuberculosis en países de ingresos medios y bajos y en países con carga alta: Una revisión sistemática y metanálisis. Bull World Health Organ. 2014;92(2):126-38. 
16. Zawedde-Muyanja S, Manabe YC, Sewankambo NK, Nakiyingi L, Nakanjako D. Xpert ${ }^{\oplus}$ MTB/RIF associated with improved treatment initiation among patients with smear-negative tuberculosis. Int J Tuberc Lung Dis. 2018; 22(12):1475-80.

17. Mugauri H, Shewade HD, Dlodlo RA, Hove S, Sibanda E. Bacteriologically confirmed pulmonary tuberculosis patients: loss to follow-up, death and delay before treatment initiation in Bulawayo, Zimbabwe from 2012-2016. Int J Infect Dis. 2018;76:6-13. Available from: https://doi.org/https://doi.org/ 10.1016/j.jijid.2018.07.012.

18. Squire SB, Belaye AK, Kashoti A, Salaniponi FML, Mundy CJF, Theobald S, et al. "Lost" smear-positive pulmonary tuberculosis cases: where are they and why did we lose them? Int J Tuberc Lung Dis. 2005;9(1):25-31.

19. Buu TN, Lönnroth K, Quy HT. Initial defaulting in the National Tuberculosis Programme in Ho Chi Minh City, Vietnam: a survey of extent, reasons and alternative actions taken following default. Int J Tuberc Lung Dis. 2003;7(8): 735-41.

20. Theron G, Zijenah L, Chanda D, Clowes P, Rachow A, Lesosky M, et al. Feasibility, accuracy, and clinical effect of point-of-care Xpert MTB/RIF testing for tuberculosis in primary-care settings in Africa: a multicentre, randomised, controlled trial. Lancet. 2014;383(9915):424-35.

21. Hanrahan CF, Haguma P, Ochom E, Kinera I, Cobelens F, Cattamanchi A, et al. Implementation of Xpert MTB/RIF in Uganda: Missed opportunities to improve diagnosis of tuberculosis. Open Forum Infect Dis. 2016;3(2):ofw068.

22. Mwansa-Kambafwile J, Maitshotlo B, Black A. Microbiologically confirmed tuberculosis: factors associated with pretreatment loss to follow-up, and time to treatment initiation. PLoS One. 2017:12(1):1-11.

23. Rao NA, Anwer T, Saleem M. Magnitude of initial default in pulmonary tuberculosis. J Pak Med Assoc. 2009;59(4):223-4.

24. Khan MS, Khan S, Godfrey-Faussett P. Default during TB diagnosis: quantifying the problem. Trop Med Int Heal. 2009;14(12):1437-41.

25. Padilla M, Mattson CL, Scheer S, Udeagu CCN, Buskin SE, Hughes AJ, et al. Locating people diagnosed with hiv for public health action: utility of hiv case surveillance and other data sources. Public Health Rep. 2018;133(2): 147-54.

26. Htwe KK, Kyaw NTT, Kumar AMV, Kyaw KWY, Oo MM, Thwin T, et al. Pretreatment loss to follow-up and treatment delay among bacteriologically-confirmed tuberculosis patients diagnosed in Mandalay region. Myanmar Trop Med Health. 2019;47(1):1-10.

27. Uganda Ministry of Health. Consolidated Guidelines on the prevention and treatment of HIV. 2018;(September). Available from: http://library.health.go. ug/publications/hivaids/consolidated-guidelines-prevention-and-treatmenthiv-uganda-1.

28. World Health Organization. Guidelines for managing advanced HIV disease and rapid initiation of antiretroviral therapy. Geneva: World Healh Organisation; 2017. [Internet]. 2017. Available from: https://www.who.int/ hiv/pub/guidelines/advanced-HIV-disease\%0A.

29. Skinner D, Claassens M. It's complicated: why do tuberculosis patients not initiate or stay adherent to treatment? A qualitative study from South Africa. BMC Infect Dis 2016;16(1):1-9. Available from: http://dx.doi.org/https://doi. org/10.1186/s12879-016-2054-5.

30. Uganda N. National Information Technology Survey [Internet]. 2018. Available from: https://www.nita.go.ug/sites/default/files/publications/ National IT Survey April 10th.pdf.

31. Gopi PG, Chandrasekaran V, Subramani R, Narayanan PR. Failure to initiate treatment for tuberculosis patients diagnosed in a community Surveyand at health FacilGopi, P. G. et al. (2005) 'failure to initiate treatment for tuberculosis patients diagnosed in a community Surveyand at health facilities under a DO. Indian J Tuberc. 2005;52:153-6.

32. Uganda Ministry of Health. Direct and Indirect costs due to Tuberculosis and proportion of Tuberculosis-affected households experiencing catastrophic costs due to TB in Uganda [Internet]. 2019. Available from: health.go.ug/sites/default/files/Tuberculosis patients cost survey Report 2019.pdf.

33. Ross JM, Cattamanchi A, Miller CR, Tatem AJ, Katamba A, Haguma P, et al. Investigating barriers to tuberculosis evaluation in Uganda using geographic information systems. Am J Trop Med Hyg. 2015;93(4):733-8.

\section{Publisher's Note}

Springer Nature remains neutral with regard to jurisdictional claims in published maps and institutional affiliations.

Ready to submit your research? Choose BMC and benefit from:

- fast, convenient online submission

- thorough peer review by experienced researchers in your field

- rapid publication on acceptance

- support for research data, including large and complex data types

- gold Open Access which fosters wider collaboration and increased citations

- maximum visibility for your research: over $100 \mathrm{M}$ website views per year

At $\mathrm{BMC}$, research is always in progress.

Learn more biomedcentral.com/submissions 